San Antonio Review • San Antonio Review (No. 5, Summer 2021)

\title{
Marlene Dietrich Played The Saw
}

\author{
D. B. Fishman
}

Published on: Apr 25, 2021

DOI: $10.21428 / 9 b 43 c d 98.042 f 5518$

License: Creative Commons Attribution 4.0 International License (CC-BY 4.0). 


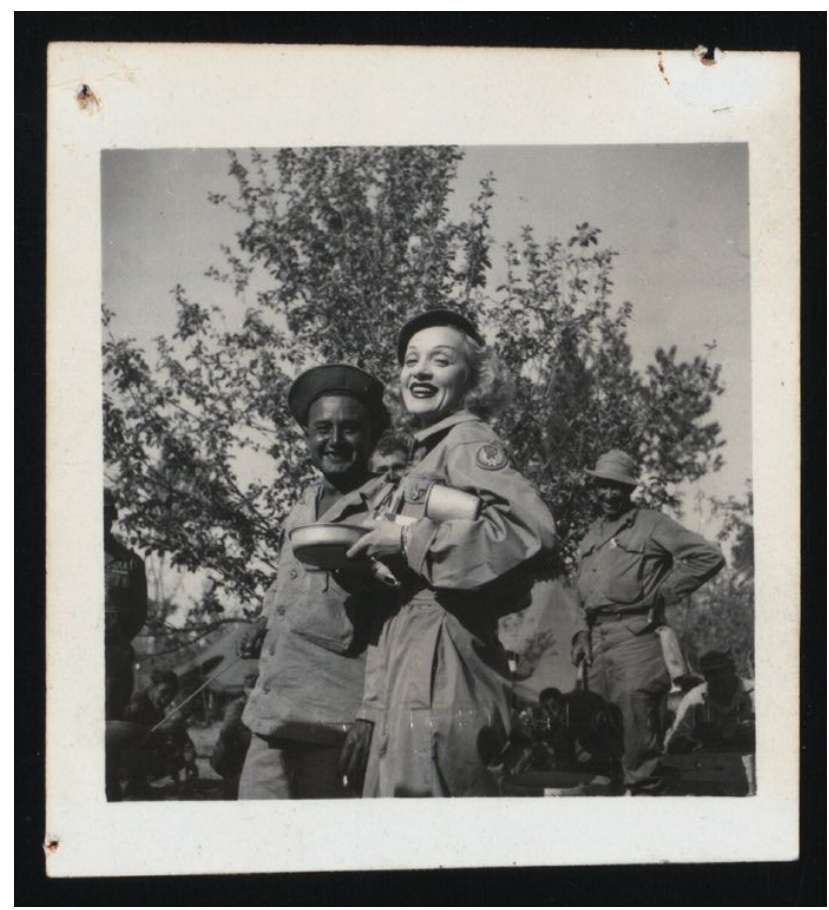

Marlene Dietrich

Played the saw

For the troops

At the USO

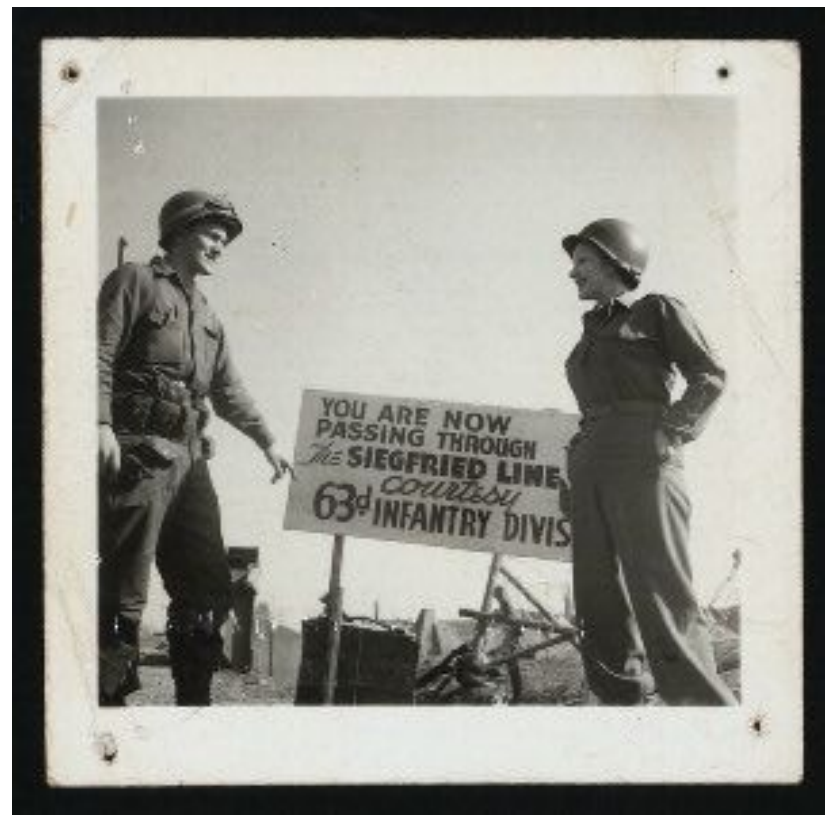

Marlene Dietrich

German femme fatale star of the silver screen

Naturalised glamorous American since 
1939

Left Hollywood for

Mere miles from German line

And with hands that studied violin

Played the saw

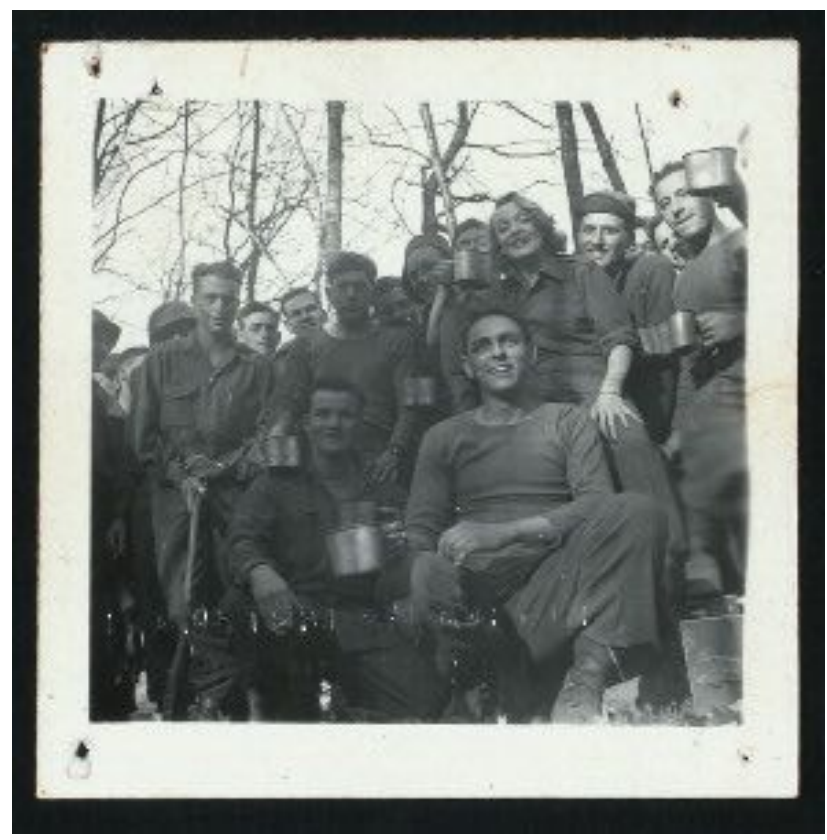

Marlene Dietrich who

The Nazi Party could not bring back With money nor the Führer's love

Crossed the Atlantic

With a 3 month supply of cosmetics,

Labelled in huge nailpolish letters to be

Read by torchlight,

2 glittering gowns and

In a black leather case

Her singing saw

To play for the troops 
Marlene Dietrich

Maria Magdalene Dietrich

Said "It was the decent thing to do";

Followed her recorded voice, with special soap,

Back to where she helped birth the talkies

And with frozen hands in the Ardennes

Played her saw for the troops

In the USO revue

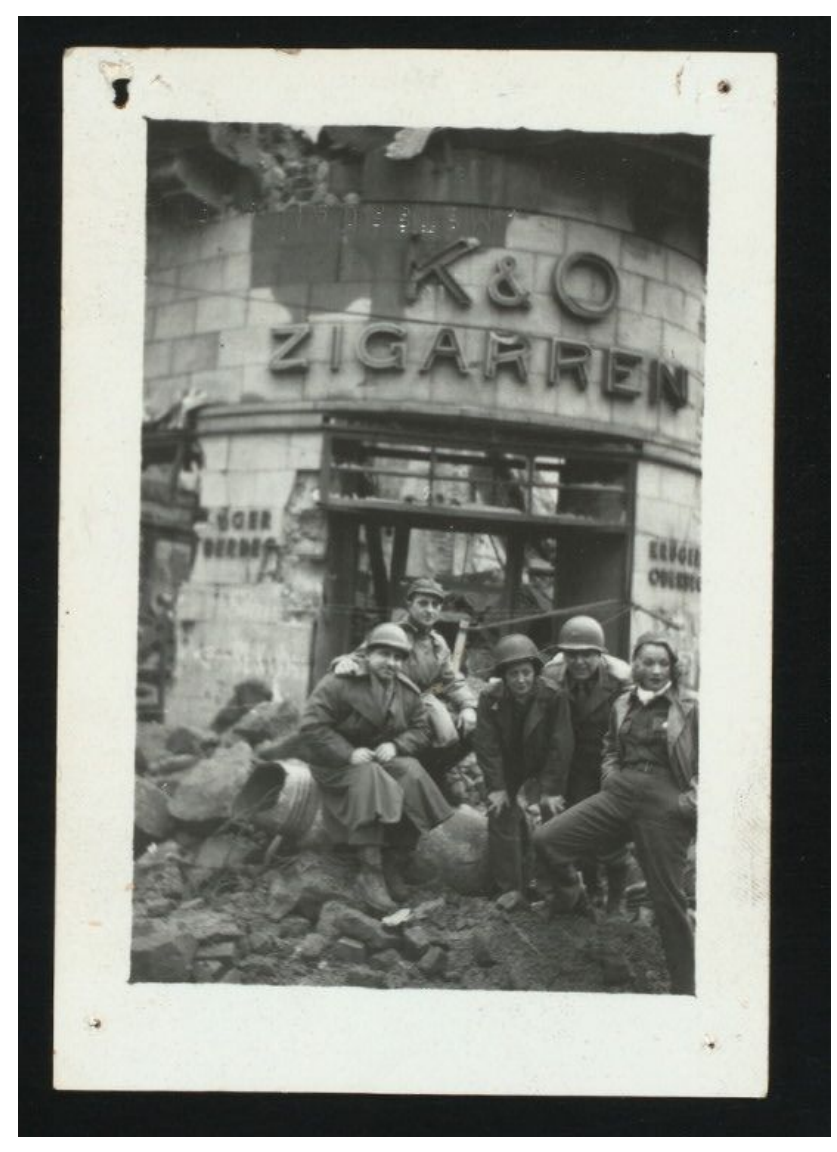

Marlene Dietrich played

On an arc of bending bladed metal, bowed

A mercurial formless freely moving

sound

A mournful, pitched howl of something

Without a mouth; an eerily haunting

Unembodied unearthly mutation of Hawaii 
A lonesome limbo call predicting

A searchlight swinging over a future

1950s Nevada B-movie highway

A tremulous oscillation, a clean vibration, free sound

That almost bypasses your ears

For something deeper

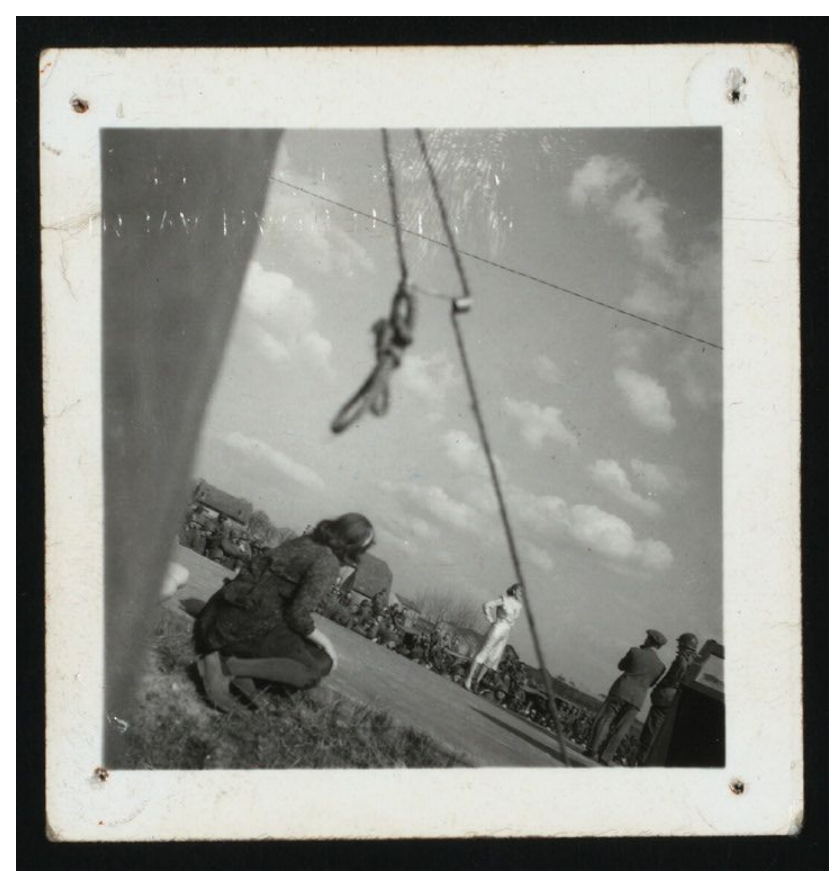

DB Fishman is an Edinburgh-born poet

living in Oxfordshire,UK.@TheDanPrism on Twitter, they write about drag, thrash metal, gender and film. Their poetry 'greatest hits', Grit for Traction, is published this year.

Photos: Billy Rose Theatre Division, The New York Public Library. "Marlene Dietrich" The New York Public Library Digital Collections. 